Revista de Economia Política, vol. 32, no 1 (126), pp. 109-127, janeiro-março/2012

\title{
Há compatibilidade entre a "tecnologia social" de Nelson e a "causalidade vebleniana" de Hodgson?
}

\author{
OCTAVIO A. C. CONCEIÇÃO*
}

Is there compatibility between Nelson's 'Social Technology' and Hodgson's 'Veblenian Causality'? This paper aims to discuss the role and the relationship among the concept of institutions and the economic growth process, through the NeoSchumpeterian and Institutionalist approaches. Both of them constitute a new research agenda differentiated and opposite to the mainstream. In the first part of the paper we discuss the research agenda proposed by Richard Nelson who emphasizes the necessity to unpack the institution concept throughout the social technology notion. In the second part we discuss Geoffrey Hodgson's contribution that suggests inserting this process in an evolutionary perspective, which has in habits, norms and social behavior his major characteristic.

Keywords: institutions; technology; economic growth; evolutionism.

JEL Classification: B52; B25.

Esse texto discute a relação entre a mudança tecnológica e institucional e o conceito de crescimento econômico. Para tanto, apresentar-se-ão os enfoques de Richard Nelson, no lado neoschumpeteriano, e o de Geoffrey Hodgson, no lado institucionalisita. A escola neoschumpeteriana vincula, de forma mais precisa, a tecnologia com as instituições, advogando a supremacia do processo de inovação e mudança tecnológica sobre os rumos do crescimento econômico. O enfoque institucionalista, por sua vez, contempla a inclusão dos indivíduos, seus hábitos e idiossincracias na definição de estratégias institucionalizadas, que originarão o referido processo. É da discussão dos pontos centrais da agenda de pesquisa proposta por

\footnotetext{
* Economista, técnico da Fundação de Economia e Estatística (FEE/RS) e professor adjunto do Programa de Pós-Graduação em Economia da Universidade Federal do Rio Grande do Sul. E-mail: octavio@ fee.tche.br. Submetido: 23/julho/2010; Aprovado: 16/novembro/2010.
} 
Nelson que trataremos no próximo item. $\mathrm{Na}$ sequência discutiremos alguns dos pontos centrais da agenda evolucionária vebleniana proposta por Hodgson.

\section{A AGENDA DE PESQUISA EVOLUCIONISTA SOBRE CRESCIMENTO E TECNOLOGIA}

Nelson (2002) argumenta que os economistas que mais vêm contribuindo para o desenvolvimento da teoria de crescimento evolucionária, ao longo dos últimos vinte anos, partem da percepção de que a teoria neoclássica de crescimento, embora assinale que a mudança tecnológica exerça papel central, é inadequada para caracterizar abstratamente tal processo. Mais especificamente, tal teoria é incapaz de tratar o processo de crescimento econômico desencadeado pela mudança tecnológica, tal como o próprio Nelson fez, em parceria com Winter, em sua obra clássica An Evolutionary Theory of Economic Change (Nelson e Winter, 1982). Em particular, o modelo neoclássico desconsidera o fato de que os esforços para o avanço tecnológico são, em grande medida, "cegos” (Nelson, 2002, p. 17).

Mesmo reconhecendo o mérito e os avanços na forma de incorporar teoricamente a mudança tecnológica - como foi o caso dos diferentes inventores e equipes de P\&D, que permitiram avançar em diferentes áreas — saliente-se, entretanto, que essas conquistas não são passíveis de ser previstas, no sentido de captar em que sentido elas irão "evoluir". A noção de que o avanço tecnológico se dá através de um "processo evolucionário" tem se desenvolvido, de forma independente, por estudiosos que atuam em várias disciplinas, como na sociologia, na história da tecnologia e na modelagem econômica (Nelson e Winter, 1982; Metcalfe, 1998; Saviotti, 1996, apud Nelson, 2002, p. 17). ${ }^{1}$

Entretanto, a contribuição dos modernos economistas evolucionários sobre mudança tecnológica, bem como suas preocupações com o papel das instituições no desenvolvimento econômico, tem tido poucos interlocutores. Por essa razão, o artigo de Nelson $(2002$, p. 18) serve como uma ponte para que as tradições intelectuais evolucionárias e institucionalistas possam seguir um caminho conjunto. Tal conjunção não constitui novidade, porque, mesmo antes que a moderna teoria neoclássica ganhasse a atual preponderância, a maior parte da análise econômica era tanto evolucionária quanto institucionalista. Por mais estranho que essa afirmação possa parecer aos céticos em relação a essa abordagem, Nelson salienta que:

\footnotetext{
${ }^{1}$ Por sugestão do parecerista anônimo, a quem agradecemos, seria importante reiterar que tanto a análise de Nelson quanto a de Hodgson têm implícito em seus argumentos que a economia institucional, por definição, é multidisciplinar. Por essa razão, a interface com sociólogos, antropólogos, biólogos é por demais eloquente. A "nova sociologia econômica" de Mark Granovetter (1985) opera nesse sentido, na medida em que as instituições, os indivíduos e o ambiente social em que ambos estão embedded, conformam o espaço da "reprodução social”. Por essa razão, tanto Veblen quanto Hodgson subentendem — mas não desconsideram - tais interações. Esse ponto contrasta com as abordagens convencionais e reforça a ontologia referida por este último autor.
} 
Thus, Adam Smith's analysis concerned with how "the division of labor is limited by the extent of the market" and, in particular, his famous pinmaking example, certainly fits the mold of what I would call evolutionary theorizing about economic change. Indeed, his analysis is very much one about the co-evolution of physical technologies and the organization of work, with the latter, I would argue, very much a notion about "institutions". In many other places in "The Wealth of Nations", Smith is expressly concerned with the broader institutional structure of nations, in a way that certainly is consonant with the perspectives of modern institutional economics. Karl Marx of course was both an evolutionary theorist and an institutional theorist. If you consider the broad scan of his writing, so too was Alfred Marshall. Thus, evolutionary growth theorizing that encompasses institutions in an essential way has a long and honorable tradition in economics. (Nelson, 2002, pp. 18 e 19).

Sob esse aspecto, a ascensão hegemônica da teoria econômica neoclássica reduziu notavelmente o escopo intelectual implícito nas referidas abordagens, tornando a análise econômica evolucionária e institucionalista um corpo estranho à teoria econômica. A dissonância em relação a essa hegemonia, no sentido de consolidação de uma trajetória própria (e institucionalista), começou a ganhar espaço nos Estados Unidos principalmente com a contribuição de Commons, que, além de Veblen e Mitchell, ajudou a definir a escola institucional norte-americana, designada de old institutional economics. Sua análise, entretanto, segundo Nelson, não era muito evolucionária. Nem Coase, que mais tarde deu substância à Nova Economia Institucional (NEI), assumiu tal caráter.

Hoje, há fortes afinidades entre o core de pressupostos e percepções da NEI - pelo menos entre aqueles pertencentes à escola de North — e a moderna economia evolucionária. ${ }^{2}$ Por isso, há razões para que ambas as correntes juntem suas forças: elas têm uma premissa central de que a ação humana e as interações são resultantes e resultam de hábitos de ação e de pensamento. Isto implica a rejeição do princípio de "maximização" enquanto "processo" de caracterização da forma como os homens agem. Há também a rejeição da noção friedmaniana, segundo a qual, se os homens não se orientam através do cálculo maximizador, comportam-se "como se" - o princípio do as if - o fizessem. Para os campos de pesquisa institucionalistas e evolucionários:

\footnotetext{
${ }^{2}$ Surpreendentemente e apesar de Schumpeter, em seus trabalhos, criticar o Antigo Institucionalismo por falta de uma teoria que lhe permitisse avançar teoricamente (Hodgson, 1998), Nelson enfatiza que: Schumpeter (1942), whose work arguably has provided the starting point for modern evolutionary economics, is seldom footnoted by self-professed institutionalists, despite the fact that Schumpeter was very much concerned with economic institutions. And Schumpeter's institutional orientation was ignored, as well, in the early writings of the evolutionary economists who cited Schumpeter as their inspiration. (Nelson, 2002, p. 19).
} 
[...] patterns of action need to be understood in behavioral terms, with improvements over time being explained as occurring through process of individual and collective learning. For economic evolutionary theorists, this exactly defines the nature of an evolutionary process. (Nelson, 2002, p. 20).

Por isso os estudiosos desses dois campos têm aumentado seus interesses na compreensão dos determinantes da performance econômica e como essa diferencia as nações ao longo do tempo. Os modernos teóricos evolucionários enfocam centralmente o que chamam de "tecnologias". E os economistas institucionalistas enfocam predominantemente as "instituições". Para Nelson, o casamento entre ambos é bastante viável. Para tanto, faz-se necessária a incorporação de alguns conceitos, como o das "rotinas" e o de "tecnologia social", como inerentemente vinculados às instituições. Assim, finalmente, incorporar-se-iam as instituições em uma teoria evolucionária de crescimento econômico.

\section{A agenda de pesquisa proposta por Nelson revisitada}

A literatura econômica recente de natureza heterodoxa ${ }^{3}$ tem alertado sobre a necessidade de se estabelecer uma nova agenda de pesquisa, que contemple, dentro de um marco analítico em gestação, a relação entre instituições, tecnologia e o processo de crescimento econômico. Nelson, em seu artigo de 2008, traz novos e mais precisos elementos para o debate teórico acerca da relação entre o processo de incorporação tecnológica, a natureza das relações institucionais e a influência recíproca e indissociável de ambos sobre a forma assumida pelo processo de crescimento. Saliente-se que o referido autor vem, há longa data, se preocupando enfaticamente com essa questão (Nelson, 1995, 1998 e 2002). Para ele, conectar instituições e crescimento implica estabelecer uma coerente análise das relações entre instituições, mudança institucional e avanço tecnológico. Nesse ponto surge o conceito de "tecnologia social”, que serve como suporte analítico e diferenciado à noção, já estabelecida, de "tecnologias físicas". Essa junção constituiria um novo tipo de análise.

Partindo dos estudos de Douglass North, da referida NEI — que, desde o início dos anos 1990, tem enfatizado a importância das right institutions como explicação central para o progresso econômico - tem-se constatado uma mudança de rumo em seu enfoque específico. A forma como as instituições afetam a eficiência, em termos de alocação econômica - bem ao gosto da visão neoclássica de convergência ao estado ótimo - vem sendo substituída, por North, por um nexo teórico mais evolucionista, em que em vez da ideia de alocação eficiente, a noção de mudança institucional passa a ser mais importante. Seu último livro (North, 2005) trilha claramente esse caminho. No campo evolucionário, um número crescente de estudos

\footnotetext{
${ }^{3}$ Por heterodoxa, entendemos as abordagens oriundas das contribuições dos neoschumpeterianos, póskeynesianos, institucionalistas e evolucionários, conforme proposição sugerida em Lawson (2006).
} 
vem trazendo as instituições para o centro de análise, particularmente no tratamento de questões ligadas ao conceito de sistemas de inovação (Dosi et al. (1988), Freeman (1988), Lundvall (1988) e Nelson (1988) apud Nelson, 2008).

A construção de uma ponte para explicar como as instituições e as mudanças institucionais se relacionam com as mudanças tecnológicas enfrenta dois obstáculos. Em primeiro lugar, não há unidade conceitual sobre o que os autores entendem que deva ser o conceito de instituição. A diversidade de significados é problemática por impedir a cumulatividade no respectivo campo de pesquisa e por obstaculizar uma maior vinculação entre eles. Em segundo lugar, a forma através da qual as instituições são tratadas na literatura sobre crescimento econômico dificultam a apreensão de como elas se ajustam ou se ligam à teoria de crescimento orientada pelo avanço tecnológico.

Um terceiro ponto que consideramos relevante é que a "desagregação" do termo instituição é de grande importância para a teoria econômica, notadamente na construção do nexo teórico para uma integração micro-macro. Até que ponto as decisões individuais, baseadas em crenças, expectativas e intuições podem se materializar no agregado ex post de um ambiente favorável ao crescimento autossustentado (?) e duradouro? E qual o papel das instituições nesse processo? Elas atuam no plano macro ou no plano micro? Suspeita-se que, conforme a definição ou corrente adotada, atuarão de uma ou outra forma. ${ }^{4}$

Embora Nelson (2008) considere viável a ponte entre instituições e mudança tecnológica, que se iniciaria com o "desempacotamento" do conceito de instituição, consideramos que não se trata apenas de desempacotá-lo, mas de estabelecer os limites conceituais nos planos micro e macro. Para desempacotar tal conceito Nelson propõe que pesquisadores e economistas estudiosos dos sistemas de inovação concentrem-se nas explicações dos métodos prevalecentes na forma de fazer as coisas em contextos diferenciados, cujas ações e interações entre as partes determinam o que é alcançado. Daí a relevância da coordenação efetiva como elemento crucial para a boa performance. Esse conjunto de ações é designado de "tecnologia social" e foi concebido em Nelson e Sampat (2001). Entretanto, para dotar de funcionalidade o referido conceito, é fundamental discutir o que vem a ser "instituição".

\section{Redefinindo o conceito de instituição}

Em uma primeira aproximação conceitual, Nelson propõe que o termo instituição, no sentido empregado no parágrafo anterior, seja definido basicamente como

\footnotetext{
${ }^{4}$ Por exemplo, na ontologia evolucionária derivada de Veblen, que se examinará na sequência, Hodgson (2007) sugere esse nexo através do conceito de reconstitutive downward causation (vide Quadro 1). Nesse sentido, o crescimento econômico seria uma propriedade emergente do ambiente micro, centrado nos hábitos, crenças e expectativas de retorno dos agentes, que se materializaria no plano agregado da macroeconomia, conforme o paradigma tecnoeconômico vigente. De outro lado, no campo neoclássico, as instituições seriam reflexo de "bons" fundamentos macroeconômicos, sintonizados com a racionalidade substantiva dos agentes, que asseguraria a eficiência sistêmica.
} 
the factors and forces that mold and hold in place social technologies (Nelson, 2008, p. 2). Tal definição seria totalmente compatível com o enfoque dado pelos autores de sua tradição teórica e tornaria clara a discussão sobre essa questão. Sob essa ótica, a dinâmica do crescimento econômico, orientada pelo avanço tecnológico, estaria inserida em um processo evolucionário, como salientado em Nelson e Winter (1982). Daí que a principal tarefa da teoria do crescimento seria construir instituições coerentes com a teoria neoschumpeteriana ou evolucionária, de forma tal que as vinculassem analiticamente com o avanço tecnológico e com as formas de fixá-lo no ambiente social, via aprendizado e conhecimento.

Como crescimento econômico, para Nelson, envolve a coevolução de tecnologias físicas e sociais, então as instituições são decisivas para seu efetivo avanço. Algumas instituições podem gerar condições sobre as quais os avanços tecnológicos possam ocorrer e outras sustentam o desenvolvimento de novas tecnologias fundamentais para a direção do crescimento. Porém, como o processo de crescimento e de avanço tecnológico ocorre sob radical incerteza, as instituições podem até mesmo atrapalhar o respectivo avanço, se não houver coordenação e estratégias adequadas em relação à orientação do paradigma tecnológico.

O processo de mudança institucional influi decisivamente na atividade econômica, porém se desenvolve de maneira muito mais difícil de dirigir e de controlar do que a mudança tecnológica. Esse argumento é também compartilhado pelas várias escolas institucionalistas, desde a NEI até os adeptos do antigo institucionalismo norte-americano de Veblen, Commons e Mitchell. ${ }^{5}$ Isso explica por que as instituições prevalecentes são arrastadas mais lentamente em relação aos aumentos da produtividade econômica e aos avanços do progresso técnico. Mais ainda, as reformas podem se dar em direções inesperadas, tortas e sinuosas, e até mesmo, como dizia Veblen, em sentidos opostos à almejada "eficiência" econômica. ${ }^{6}$

\section{Como desempacotar o conceito de instituições?}

A questão sobre qual o significado do termo instituição deve ser respondida de maneira consistente com o caminho pelo qual o termo será utilizado. Tal noção não pode ser empregada fora do seu respectivo contexto. Por exemplo, é comum entre os economistas no campo da NEI definir instituições como "as regras básicas do jogo", no sentido de um amplo regime legal, das formas de fazer cumprir as regras (enforcement segundo North, 1990) e de assegurar normas que restrinjam o comportamento. Esse padrão conceitual também associa instituições com "estruturas de governança”, as quais moldam os vários matizes da atividade econômica, tais como as instituições financeiras das nações ou as formas como as firmas se

\footnotetext{
${ }^{5}$ Essa questão é discutida mais detalhadamente em Conceição (2008).

${ }^{6}$ Como exemplo concreto de evolução das instituições Nelson cita o caso da sustentação das biotecnologias nos Estados Unidos, em que procura demonstrar quão difícil é avaliar se as instituições vigentes são adequadas, se funcionam bem, se precisam de reformas e de que tipo.
} 
organizam. Esta segunda vertente é, em realidade, uma variante conceitual em relação à definição de North, que tem Williamson (1985) como principal expoente. Tais noções, aparentemente díspares, são oriundas da mesma escola, que tem ambos os autores como importantes referências. Mesmo não sendo antagônicas, nem desvinculadas, estas duas noções são bastante diversas, resultando de posições diferentes de North e Williamson. Embora o primeiro reitere sua crítica ao neoclassicismo, ele não é anti-mainstream, mas, junto com Williamson, mantém certo distanciamento em relação a qualquer referência à Veblen. De "regras do jogo" a "estruturas de governança" muitas outras noções de instituição se interpõem, tornando difícil, se não quase impossível, uma definição mais precisa (ou "desempacotada"). E é nesse sentido que Nelson reivindica uma maior depuração conceitual.

Em uma linha de pensamento mais próxima de Veblen (e, portanto, mais distante da NEI) há outro grupo de economistas que associa instituições aos hábitos, costumes, padrões de comportamento standard ou esperados, que atuam em diferentes contextos. Como exemplo, poderia se empregar a aceitação do dinheiro na troca por bens e serviços, ou outros aspectos comportamentais. Veblen é a referência central desses autores, que vinculam as instituições ao contexto evolucionário. Para Nelson, com o que concordamos, a principal referência analítica dessa corrente, na atualidade, é Hodgson $(1988,2006)$. É importante salientar que para essa linha analítica - que poderíamos designar de "institucionalismo evolucionário" ou "neoinstitucionalistas" ou, como preferem, herdeiros do original institutional economics ${ }^{7}$ - o que importa é a forma através da qual as coisas são feitas, e não o conjunto de regras, ou a estrutura de governança que as orientam, ou que restringem o comportamento humano. Embora conectadas, tais abordagens institucionalistas (leia-se a NEI x Hodgson) são bastante diferentes. Mais ainda, esta linha de pensamento representada por Hodgson vem se notabilizando por vincular Veblen à Darwin.

Nelson salienta que, enquanto alguns autores usam o termo instituição para se referir a variáveis abstratas (como a consistência e a percepção jurídica das regras legais em uma sociedade, a moderna pesquisa nas universidades ou o uso generalizado da moeda nas trocas), outros o associam a entidades concretas particulares (como a Suprema Corte dos USA, o sistema de pesquisa na agricultura da Universidade da Califórnia ou o Bank of England). Às vezes, a ênfase do termo está associada a questões comportamentais e legais, outras vezes a "entidades" ou organizações físicas. Consideramos que tal orientação deve pender para o primeiro enfoque, que, ao retomar a tradição de Veblen, associa instituições ao conjunto de normas, regras, hábitos e sua evolução. O formato "físico" decorre do caráter "abstrato" das regras de comportamento.

\footnotetext{
${ }^{7}$ Sem procurar esgotar o tema, há uma série de abordagens institucionalistas que se digladiam, embora, atualmente, tenha ocorrido uma clara linha de convergência. Para efeitos de simplificação dividiríamos os institucionalistas em três correntes: o Antigo Institucionalismo, o Neoinstitucionalismo (no qual incluimos Hodgson) e a NEI.
} 
Nelson afirma, ainda, que em textos sobre sistemas de inovação (em nível nacional, regional e setorial), o termo é usado para se referir a entidades concretas, tais como o que as firmas fazem, quais são os seus padrões de cooperação e competição, qual o papel das sociedades técnicas, dos centros de pesquisa e das universidades, qual a relação indústria-universidade, leis de patentes, programas públicos etc. Portanto, é dentro desse amplo espectro de definições que oscila o conceito de instituição. Daí a necessidade de depurá-lo.

\section{O conceito de instituição e tecnologia social}

Nelson e Sampat (2001) propõem definir instituição como a ampla gama de estudos que enfocam o caráter e os fatores que sustentam a forma de fazer as coisas em contextos em que as ações e interações entre diferentes agentes determinam o que é obtido. Por isso o conceito de "tecnologia social" parece mais adequado, tanto porque envolve uma ampla conceituação de atividade econômica — desde sua forma mais padrão, entendida como a forma de se produzir algo, ou, mais genericamente, na produção de algo útil -, quanto uma ampla visão que o termo incorpora e sugere. Para estes autores, uma atividade ou uma série delas (como produzir um rádio, plantar arroz, realizar uma cirurgia, fazer um bolo, começar um novo negócio) envolve um conjunto de ações ou procedimentos que precisam ser feitos (tais como os procedimentos envolvidos na preparação de um bolo). Esses passos exigem insumos particulares e, em alguns casos, equipamentos, infraestrutura etc.

Normalmente, os economistas usam o termo tecnologia para designar procedimentos que precisam ser feitos para se obter certos resultados. Nesse sentido, a tecnologia pode ser entendida com "física”; já a forma como o trabalho é dividido e coordenado constitui a tecnologia "social". Todas as atividades econômicas envolvem tanto tecnologias físicas como sociais, em que a produtividade e a efetividade de uma dada atividade são determinadas por ambas. As tecnologias sociais amplamente empregadas na economia são capacitadas ou restringidas por leis, normas, expectativas, estruturas de governança, e por mecanismos, costumes e modos de organização e de transação. Ou seja, tais fatores sustentam e padronizam determinadas e (específicas) tecnologias sociais e, em contrapartida, podem tornar difíceis, inviáveis e não factíveis outras tecnologias, que são excluídas socialmente. Daí a sugestão em se definir instituições de maneira diferenciada, denotando estruturas e forças que moldam e sustentam, em locais específicos, as tecnologias sociais.

Tal padrão conceitual — qual seja, a concepção de que a tecnologia social requer instituições que a sustentem e a reforcem - é absolutamente compatível com a literatura de sistemas de inovação, o que estabelece um vínculo com o pensamento neoschumpeteriano. Assim, o sistema de P\&D industrial pode ser visto como um conjunto de atividades relacionadas tanto às tecnologias físicas quanto às tecnologias sociais. No primeiro caso incluir-se-iam os procedimentos, laboratórios, centros de pesquisa etc.; no segundo, a divisão do trabalho entre cientistas e as várias estruturas de coordenação e de direção. A partir daí emergem a organi- 
zação e as estruturas de governança da pesquisa em laboratórios industriais, que constituim a instituição-chave para a capacitação e sustentação da tecnologia social.

Como conclusão, Nelson propõe que as tecnologias sociais possam ser "autoinstitucionalizadas" de várias maneiras. Em primeiro lugar, comportamentos de costumes, modos de interação e de organização se autorreforçam (self reinforcing) porque são esperados, são familiares, em que qualquer ação diferente desse padrão provocaria uma reação inibidora. Em segundo lugar, as tecnologias sociais tendem a existir dentro de sistemas que vinculam umas às outras, autossustentando-as mutuamente. Em terceiro lugar, as tecnologias sociais, bem como as tecnologias físicas, tendem a progredir e avançar ao longo do tempo, como resultado da experiência acumulada, que é dividida entre ambas de maneira deliberada ou inadvertidamente, o que também revela seu caráter duradouro e cumulativo.

Tal quadro estabelece um padrão de sinergias e de estabilidade que permite à sociedade avançar, ora criando novas tecnologias sociais, ora substituindo as velhas. Isto reforça o argumento segundo o qual esta agenda de pesquisa deve aprofundar-se no papel das instituições e da mudança tecnológica e institucional sobre os rumos do processo de crescimento econômico.

A questão que se coloca aqui é se a sugestão levada a efeito por Nelson de inserir as instituições dentro do conceito de "tecnologias sociais" seria, do ponto de vista conceitual, suficiente para contemplar a desagregação do conceito de instituição. Apesar de concordarmos com sua incursão dentro das abordagens institucionalistas, Nelson pouco esclarece a respeito do papel das instituições. Em realidade, seu conceito de instituição gravita em torno do sistema de P\&D e serviria como suporte ao avanço tecnológico. $\mathrm{E}$, mesmo sob uma perspectiva de análise evolucionista, o papel das instituições abrange aspectos bem mais complexos e amplos do que servir de suporte ao ambiente de inovação e mudança tecnológica. Elas, seguindo a tradição de Veblen, que o próprio Nelson destaca, moldam opiniões, crenças e hábitos, mudando o comportamento dos indivíduos, os quais, por sua vez, tomam decisões e criam seus hábitos em consonância com os avanços tecnológicos. E como se viu, Nelson, sob esse aspecto, pouco argumenta. Não há em sua avaliação a ênfase no sentido de incorporar o papel dos indivíduos no processo de mudança institucional e tecnológica. A despeito da relevância do conceito de tecnologia social sobre o ambiente econômico regional e suas características específicas, ele pouco discorre sobre a importância dos indivíduos na definição dos respectivos hábitos, normas e padrões de conduta que lhes são específicos. Daí a importância da contribuição de Hodgson, que é discutida na sequência.

\section{HODGSON E A ONTOLOGIA EVOLUCIONÁRIA DERIVADA DE VEBLEN}

Geoffrey Hodgson, de forma complementar a Nelson, propõe um novo enfoque para a análise institucionalista evolucionária, que reforça a vinculação entre instituições e evolucionismo, não apenas a partir da forma de "desagregação" ou 
desempacotamento reivindicada por Nelson, mas pela proposição de uma nova ontologia evolucionária centrada em Veblen.

Em outros termos, o caráter evolucionário do processo de crescimento econômico decorre da natureza da relação entre indivíduos e instituições, que, no plano das propriedades de emergência, influencia, através do conceito de reconstitutive downward causation, os hábitos (padrões de conduta, estratégias e decisões) que estimulam o animal spirit, no sentido da constituição de instituições compatíveis com a direção em que se delineia o processo de crescimento.

Crescimento se dá no plano mais elevado, das instituições, que reforça, mas que também é reforçado, pelo padrão de hábito e de conduta dos indivíduos. Esses elementos revelam parte da ontologia a que se refere Hodgson. Mas, para tanto, faz-se necessária uma discussão a respeito das noções darwinianas de causalidade e intencionalidade. Estas se relacionam com o conceito proposto por Veblen de causação cumulativa, que, aliás, é frequentemente referido no campo da economia institucional. O que Hodgson traz de novo é que essa discussão tem raízes darwinianas profundas e integram o que ele designa de ontologia evolucionária de Veblen. O conceito de reconstitutive downward causation integra instituições e indivíduos dentro dessa proposição.

Quadro 1: Reconstitutive downward causation
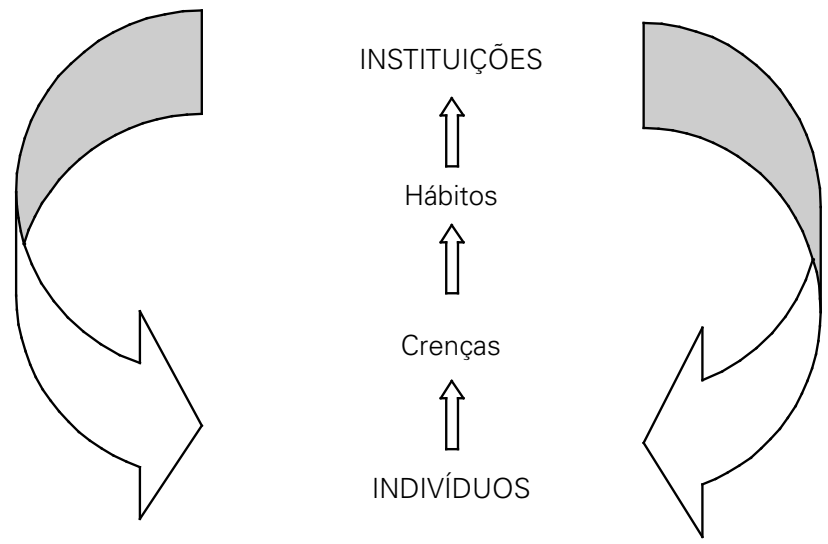

(Processo de crescimento)

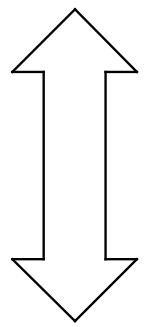

(Processo de decisão)

\section{Intencionalidade e causalidade darwiniana}

Muito se discute no campo da Economia Institucional sobre a importância da "montagem" de um adequado ambiente institucional para o estabelecimento de um sólido, estável e relativamente duradouro estágio de crescimento econômico. Tal quadro decorre também de adequada e consequente estabilidade macroeconômica. Entretanto, é bastante comum estabelecer-se esta relação de causalidade, quase automática, entre crescimento duradouro e estabilidade macroeconômica. Normalmente se infere que a última se constitui, por definição, na condição necessária e 
suficiente para que o primeiro processo triunfe. Vários autores contemplam, sem questionamentos, essa assertiva, principalmente no campo da teoria convencional dos modelos standard (Nelson, 2002). O mesmo preceito pode ser aplicado para alguns autores mais próximos da NEI, que aceitam esta relação de determinação. Deduz-se daí que, para os mesmos, o processo de crescimento econômico é, de alguma forma, fruto da "intencionalidade" humana, no sentido de trilhar ou perseguir "bons" fundamentos macroeconômicos. Em outros termos, e correndo-se o risco de simplificar demasiadamente a análise, não seria surpreendente deduzir-se que bastaria seguir, normativamente, o "ideal" estabelecido no plano teórico de uma "adequada" teoria econômica para garantir-se o crescimento autossustentado e duradouro. Tal perspectiva é bastante previsível e roteiristíca. Não se discorda que tal prognóstico possa vir a se concretizar, mas sua determinação está longe de ser previsível.

Esta, a propósito, é também uma questão central suscitada por Keynes em sua Teoria Geral, visto que a incerteza em um campo complexo como a economia é intraduzível em termos probabilísticos, em face do caráter ergódico da realidade econômica e social. A mesma questão da indeterminação, em face da vigência da incerteza, é enfatizada pelos seguidores da antiga tradição institucionalista. Assim, poder-se-ia formular a seguinte questão: há ou não intencionalidade no desencadeamento do processo de crescimento econômico? A intencionalidade dos indivíduos (ou governantes) em direção a tal desígnio garante sua manifestação ou ocorrência? Considera-se que não, visto que inúmeros outros fatores concorreriam para sua emergência. Crescimento econômico é complexo demais para originar-se de maneira apenas intencional. As mudanças institucionais, tecnológicas e sociais devem caminhar simultânea e articuladamente na direção desse objetivo, o que não é algo historicamente fácil de obter. Uma vez alcançado um ambiente favorável ao processo de crescimento econômico, engendra-se sistemicamente uma articulação otimista em relação às perspectivas de crescimento, estimulando o animal spirit a inserir-se intencionalmente nesse objetivo. Em termos veblenianos, há explicitamente inclusão da questão de intencionalidade, que deriva da causalidade e dos princípios darwinianos de seleção, variação e herança.

A questão que se poderia formular aqui é o que Darwin tem a ver com essa história? De que forma sua concepção estabelece alguma relação com a complexa determinação do processo de crescimento econômico? A resposta envolve uma discussão acerca da noção de crescimento econômico nos institucionalistas e como essa noção se articula com a abordagem de Thorstein Veblen. Neste sentido, como tem sido enfatizado pelas correntes contemporâneas vinculadas a Veblen, há sua absoluta filiação ao pensamento de Darwin. Resumidamente, o processo de crescimento econômico relaciona-se à maneira como o desenho institucional toma forma em determinado espaço econômico, o qual, por sua vez, é reflexo da forma como operaram os processos de seleção, variação e herança ao longo de sua trajetória evolutiva.

É nesse sentido que as agendas de pesquisa em economia institucional e economia evolucionária vêm se aproximando, tanto metodológica quanto ontologica- 
mente, se é que foram tão distantes assim no passado. O que as unifica são os referidos princípios darwinianos de variação, seleção e herança, que estão presentes na tradição do antigo institucionalismo de Thorstein Veblen. Assim, o darwinismo vem sendo incorporado às ciências sociais, em geral, e à economia, em particular, a partir de uma releitura da contribuição institucionalista vebleniana, que só agora passa a ser compreendida. A linha de argumentação darwiniana aplicada à "evolução socioeconômica", ao não aceitar reducionismo biológico (princípio segundo o qual o todo é compreendido a partir da descrição das partes que o integram), vem buscando incorporar pressupostos relativos à causalidade e às explicações causais. E isso, ao contrário do senso comum, não implica subestimar, nem ignorar a noção de "intencionalidade humana": causalidade não implica ausência de intenção. Mas significa que tais pressupostos exigem que a mesma também esteja sujeita à explicação causal.

O termo "economia evolucionária" descreve uma variedade de visões e abordagens, algumas das quais incorporam ideias ou analogias oriundas da biologia. Ocorre que, mesmo entre os autores que incorporam aspectos da biologia, como é o caso de Nelson e Winter (1982), há relutância em utilizar ou fazer referência a Darwin. A resistência à Darwin nas ciências sociais se dá principalmente porque alguns críticos o opõem à noção de intencionalidade humana, o que caracterizaria uma visão "determinista" e "mecanicista". ${ }^{8}$ Porém, o que caracteriza o darwinismo é o emprego dos mecanismos de variação, seleção e herança, que estão bastante disseminados entre os economistas evolucionários, e que constituem um amplo potencial de aplicação no campo social e econômico, bem como nos fenômenos biológicos. Portanto, sob certas condições, uma ampla e geral versão do darwinismo pode ser aplicada a sistemas complexos, abertos e em evolução, como tem enfatizado autores como Veblen (1919), Campbell (1965), Dawkins (1983) e Hodgson $(2002,2004)$, conforme cita o próprio Hodgson (2004a).

Algumas das implicações do darwinismo sobre as ciências sociais se concentram estritamente em questões de natureza ontológica, particularmente relacionadas à causalidade. Causalidade, desde Aristóteles, é identificada segundo quatro tipos: a formal, a material, a eficiente e a final. Antigamente, tal noção assumia um significado mais amplo do que o conferido atualmente, pois incluía aspectos rela-

\footnotetext{
${ }^{8}$ Muito se tem dito a respeito do "darwinismo social”, reforçando, principalmente ao longo do século $\mathrm{XX}$, uma grande rejeição de seus pressupostos aplicados às ciências sociais. A falta de compreensão das ideias evolucionárias - que só nas últimas décadas do século XX começam a ser apreendidas, a partir dos princípios de variação, seleção e herança - responde pelo mal-entendido enfoque "social" de Darwin. Esse, até então, era pautado pelo princípio da "sobrevivência dos mais aptos". Para explicitar este fato, Hodgson (2004b, p. 428) - para não fugirmos da sua contribuição mais recente - parte do famoso afresco de Diego Rivera, intitulado Man at the Crossroads, no qual o famoso pintor mexicano inclui no lado direito da gravura símbolos da liberação: including Karl Marx, Vladimir Illych Lenin, Leon Trotsky, several young female athletes and the massed proletariat. To the darker left of the mural are sinister battalions of marching gas-masked soldiers, the ancient statue of a fearsome god, and the seated figure of a bearded Charles Darwin. These conceptions of good and evil, progress and regress, and light and shade, were prominent in much of Western social science for the next fifty years.
} 
cionados à natureza, à forma e à constituição material de um fenômeno, em termos de causas "formais" e "materiais". Atualmente é adotado um sentido mais restrito da palavra, significando que fatores específicos levam a um efeito. Conforme Jochen Runde (1998, p. 154, apud Hodgson, 2004, p. 177): a cause of an event [includes] anything that contributes, or makes a difference, to the realisation of that event in one or more of its aspects. Neste sentido, do ponto de vista mais restrito, Aristóteles distingue causalidade "eficiente" de causalidade "final", sendo que a primeira não necessariamente significa "ótima" ou qualquer outro tipo de resultado, mas simplesmente capacidade de ter um efeito; e a última, também conhecida como sufficient reason, tem um caráter teleológico, no sentido de que é dirigida por uma intenção, propósito ou objetivo. Portanto, para o darwinismo é central que a intencionalidade deva ser capaz de dar explicações em termos de movimentos e transferências. ${ }^{9}$

Darwin não somente proclamou que as espécies evoluíam, mas também apontou para os mecanismos causais da evolução: a ciência envolvia um compromisso com explicações causais. O trabalho de Darwin ao longo de toda a sua vida foi marcado pela ambição de estender o campo de "explicação causal" para todas as áreas que eram dominadas por tabus de doutrinas religiosas. Mesmo antes de formular sua teoria de seleção natural, considerava que a origem da espécie humana e sua capacidade única de reflexão e deliberação racional poderiam, a princípio, ser explicadas pela ciência. Ele rejeitou explicações de fenômenos naturais em termos de projetos, para centrar-se no detalhamento de causas físicas ou "eficientes", que haviam se acumulado na emergência de fenômenos elaborados durante longos períodos de tempo. Também não acreditava que as variações emergissem espontaneamente, no sentido de surgirem ou aparecerem sem uma causa. Darwin acreditava que tais "variações acidentais" deveriam ser "produzidas por causas desconhecidas" ao invés de incorporar a noção de eventos espontâneos ou sem causa. Ou seja, não acreditava que as variações surgissem sem qualquer causa a priori. Para ele, só devido à nossa ignorância é que elas apareceriam como "espontâneas". Assim, mesmo quando mecanismos causais fossem ilusórios ou desconhecidos, seria tarefa do cientista tentar desvendá-los.

Darwin sustentou que resultados complexos poderiam ser explicados em termos de uma detalhada sucessão e acumulação, passo a passo, de mecanismos causais, daí a suprema importância da "ação cumulativa da seleção" (Darwin, 1859, p. 43 apud Hodgson, 2004a, p. 180). Essa sequência de causalidade, aliás, esteve sempre presente na análise vebleniana. Portanto, Darwin não apenas argumentou que a seleção natural operava lentamente, mas também sustentou, principalmente,

\footnotetext{
${ }^{9}$ Nas palavras de Hodgson (2004a, p. 178): Intentions are real and intentions are causes but intentions do not require an entirely different notion of causality. The causes of intentions and their causal effects have to be explained, in terms that include the important role of mental prefiguration and judgement. But these mental aspects also involve movements of matter and transfers of energy or momentum, within the brain. They are special causal mechanisms but not an entirely different (teleological) category of cause.
} 
que cada passo era suscetível a explicações causais. Com isso, sua doutrina sustentava, em particular, os mais sofisticados e complexos resultados da evolução, tais como a visão e a consciência humana. Tais fenômenos, para ele, eram suscetíveis de explicações causais, de maneira que não haveria nem um súbito nem um milagroso salto na evolução da intencionalidade humana. Nesse sentido, o darwinismo não excluiu a noção de intencionalidade. Segundo Hodgson (2004a, p. 182):

Darwinism brought not only human evolution, but also the human mind and consciousness within the realms of science. Science proceeds by extending the domain of causal explanation. Much of human physiology could be explained by natural selection; Darwinism thus brought the frontier of scientific enquiry to the inner workings of the human mind.

Outra objeção a ser removida a respeito das ideias darwinianas em relação às ciências sociais é a de que a evolução é cega, ignorando a intenção consciente e os planos dos indivíduos. As intenções humanas são parte da realidade social e as interações sociais envolvem expectativas das pessoas ou indivíduos em relação às intenções dos outros indivíduos.

Sob a perspectiva darwiniana, portanto, todos os resultados têm de ser explicados de forma vinculada a um processo causal: não há nada teleológico ou orientado por natureza. Tudo deve se submeter às explicações causais em termos científicos. Isso constitui parte da visão teórica e ontológica de Darwin. ${ }^{10}$

\section{A ênfase darwiniana de Veblen na causação}

Em Veblen and Darwinism (2004), Hodgson afirma que uma série de incompreensões circunda a questão do darwinismo em sua relação com as ciências sociais. E, contrariamente ao senso comum, o darwinismo não sustenta nenhuma forma de racismo, nacionalismo ou imperialismo, nem estabelece nenhuma justificativa moral no sentido da sobrevivência dos mais aptos. Mais ainda: darwinismo não implica a inevitabilidade de conflitos entre militantes; nem que as desigualdades humanas de poder sejam inevitáveis; que a cooperação e o altruísmo não sejam importantes ou não sejam naturais; que a evolução sempre leve à otimização ou ao progresso; que os fenômenos sociais possam ou devam ser explicados em termos de seus gens tomados isoladamente; que as intenções humanas não sejam importantes; ou que a ação humana seja cega ou mecanicista (Hodgson, 2004, p. 345). Isto porque:

Above all, Darwinism means causal explanation, where a cause is understood as necessarily involving transfers of matter or energy. Divine,

\footnotetext{
${ }^{10}$ Ainda segundo Hodgson (2004a, p. 183): Darwinism invokes both a theory of natural selection and a universal commitment to causal explanations. This brings us right back to the aforementioned central lacuna in social theory - the widespread failure to provide an adequate causal explanation of human intentionality and human motives.
} 
spiritual, miraculous or uncaused causes are ruled out. Explanations of outcomes are in terms of connected causal sequences. In addition, Darwinism upholds that the evolution of organisms and complex systems involves the mechanisms of variation, inheritance and selection.

Veblen compreendeu e endossou os princípios de causalidade que foram fundamentais ao darwinismo. Para Veblen, a rejeição darwiniana da teleologia se tornou a base necessária de um científico e "pós-darwiniano" approach para a economia e para a ciência social. Há uma abundante evidência de que Veblen compreendeu o darwinismo, em sua maior parte, como, fundamentalmente, sendo um compromisso no detalhamento e análise sequencial causal. Em Hodgson (2004) há uma série de citações extraídas dos escritos de Veblen que confirmam isto. Embora Darwin não utilizasse o termo "causação cumulativa", o mesmo é importante para sublinhar a forma pelo qual Veblen o via como vinculado ao darwinismo. Por exemplo, em 1907, Veblen escreveu que:

[...] in the Darwinian scheme of thought, the continuity sought in and imputed to the facts is a continuity of cause and effect. It is a scheme of blindly cumulative causation, in which there is no trend, no final term, no consummation. The sequence is controlled by nothing but the vis a tergo of brute causation, and is essentially mechanical. (Veblen, 1907, p. 304, apud Hodgson, 2004, p. 346)

Enquanto Veblen cunhava o termo causação cumulativa, utilizava-o primeiramente para se referir às sequências cumulativas de causa e efeito. Assim como ocorre com outros autores, o termo "causação circular" leva a diferentes significados, que, em linguagem moderna, poderia associar-se a processos não lineares de retornos positivos. Por exemplo, em seu clássico artigo sobre "retornos crescentes", Allyn Young (1928, p. 533, apud Hodgson, 2004, p. 346) escreveu que changes becomes progressive and propagates itself in a cumulative way. Nicholas Kaldor, um de seus estudiosos, tornou extensivo o uso da noção de feedback positivo da “causação cumulativa” de Young (Kaldor, 1985, apud Hodgson, 2004). Gunnar Myrdal de maneira independente também levou a ideia de causação cumulativa para os mecanismos de feedback positivos para a economia monetária do colega sueco economista Knut Wicksell.

Veblen empregou a ideia de uma cadeia histórica sem quebra de causa e efeito para minar os pressupostos do mainstream econômico. $\mathrm{O}$ uso feito por ele sobre as injunções metodológicas darwinianas levaram-no a uma poderosa crítica. Isto porque, em Veblen, o agente humano era assunto de um processo evolucionário e jamais poderia ser tido como fixo ou dado. Portanto, uma avaliação causal da interação entre indivíduo e estrutura social tinha que ser providenciada. E esse "acerto de contas" causal não deveria parar no indivíduo, mas deveria também tentar explicar a origem dos objetivos e preferências psicológicas.

Para Veblen, o problema com o mainstream econômico era que o mesmo não 
forneceu uma explicação causal e evolucionária nem do "homem econômico racional", nem de sua dada função de preferência. Como a racionalidade e as preferências apareceram na evolução humana? Que causas e processos a trouxeram? Como e quando elas se formaram no desenvolvimento de cada indivíduo humano? Para Veblen, a fuga desses princípios evolucionários seria algo impossível de ser aceita analiticamente. Assim, o darwinismo significou não somente a crítica na intervenção divina, mas também a rejeição das funções de preferência concebidas imanentemente. Como resultado, a hipótese universal da economia neoclássica de uma passiva e substancialmente inerte e imutavelmente dada natureza humana tinha que ser criticada (Veblen, 1898b, p. 389, apud Hodgson, 2004, p. 247).

A posição de Veblen, de forma retrospectiva, é estritamente moderna no contexto dos desenvolvimentos recentes na filosofia, psicologia, sociologia, antropologia e economia. E sua posição é muito mais viável hoje, conquanto ocorreram melhoramentos e avanços, principalmente na substituição da filosofia kantiana de Veblen por uma forma mais adequada de realismo. ${ }^{11}$

A maior parte das proposições que compõem os "fundamentos filosóficos do institucionalismo vebleniano" são ontológicas e referentes à natureza do ser social, envolvendo causalidade, evolução, pensamento populacional darwiniano e muito mais. Assim, o institucionalismo vebleniano, tanto na sua forma original quanto na ressuscitada, pode reivindicar uma ontologia particular. Ela contrasta com muitos outros approaches encontrados nos heterodoxos e no mainstream. Por exemplo, a visão de Veblen em relação à fundação instintiva da inteligência contrasta com as visões predominantes dos cientistas sociais heterodoxos e ortodoxos, que veem o instinto e a inteligência como sendo opostos. Além disso, a insistência de Veblen no sentido de que as hipóteses relativas às capacidades humanas radicais tenham que ser consistentes com as explicações evolucionárias, em termos darwinianos, também está ausente na maior parte do pensamento mainstream e heterodoxo. Embora Veblen não tenha desenvolvido e solucionado uma adequada ontologia social propriamente dita, sua instância geral darwiniana e evolucionária aponta para uma ontologia potencialmente fértil assentada em futuros trabalhos teóricos. Em parte, a abordagem vebleniana ressuscitada enfoca-se na natureza algorítmica e incremental da tomada de decisão. Sua orientação se dá em direção aos processos antes do que ao equilíbrio. Tanto a realidade social, quanto as capacidades indivi-

\footnotetext{
${ }^{11}$ Hodgson (2004, pp. 246-247) sugere 27 proposições fundamentais do institucionalismo de Veblen. Em sentido crítico, identifica seis proposições básicas negativas do institucionalismo de Veblen, que inclui a rejeição ao positivismo, ao individualismo metodológico e ao coletivismo metodológico, desde que adequadamente definidos. Além disso, para Hodgson, Veblen endossa treze proposições básicas positivas adicionais (incluindo o princípio da causação universal, o princípio da explicação evolucionária e a ideia de reconstitutive downward causation). Em conjunto, essas dezenove proposições não são suficientes, fazendo-se necessário elementos-chave adicionais. Estes elementos adicionais, porém: [...] were unclear, underdeveloped or absent in Veblen's works' I add a further eight propositions (including a layered ontology and an explicit focus on emergent properties) that are 'vital for a Veblenian theoretical system rebuilt on emergentist foundations' (Hodgson, 2004, p. 247). Essas 27 proposições esquematizam parte dos fundamentos filosóficos do institucionalismo vebleniano.
} 
duais são concebidas em termos dos vários sistemas de regras processuais. Seguindo Veblen, tais sistemas de regras são substituídos dentro de estruturas darwinianas generalizadas, em que os princípios de variação, retenção e seleção são usados para ajudar a explicar sua evolução.

É nesse sentido que Hodgson (2006) propõe a noção de reconstitutive downward causation, como elemento fundamental à definição dos hábitos, que constituirão o arcabouço institucional. A proximidade teórica com North (Hodgson, 2007, p. 330) - que também reconhece a importância dos modelos mentais, que levam à estrutura econômica e, finalmente, às instituições - sugere uma convergência entre o novo e o antigo institucionalismo, que reabilita o conceito de preferências endógenas e a importância da racionalidade individual, formada cultural e institucionalmente. Esses pontos reforçam a existência de uma ontologia evolucionária vebleniana.

Daí a proposição de Hodgson de que esses e outros elementos coincidem com uma mudança de gestalt nas ciências sociais, fora das concepções de mudança incremental e de equilíbrio (em que qualquer coisa potencialmente colide com outra), para uma noção de interconectividade dentro dos sistemas sociais, composta essencialmente de estruturas e processos algorítmicos de regras (Hodgson, 2006, p. 8). Por conta dessa nova gestalt, e, mais particularmente, devido aos recentes desenvolvimentos do novo institucionalismo, bem como do velho, o que emergirá como "economia institucional”, nas próximas décadas, pode tornar-se muito diferente do que predominou nos anos 1980 e 1990, delineando uma genealogia com o velho, bem como com o novo institucionalismo.

\section{CONCLUSÃO}

O que a discussão levada a efeito nesse texto permite concluir é que tanto a agenda de pesquisa de Nelson quanto a de Hodgson têm permitido avançar no campo da economia institucional e evolucionária rumo a uma depuração do termo instituição. Por conta disso, vem emergindo um novo corpo analítico que revitaliza, em moldes contemporâneos, o ideário institucionalista esboçado por Veblen há pouco mais de um século.

A contribuição de Nelson reconhece a importância das várias abordagens institucionalistas, mas reitera que seu "desempacotamento" é decisivo para estabelecer avanços analíticos. E esses se dariam no sentido de tentar contemplar mais adequadamente o espectro de mudanças tecnológicas e institucionais que se sobrepõem, à medida que o processo de crescimento avança. Assim, propõe uma aproximação das instituições aos setores ligados à mudança tecnológica e seu desenvolvimento, que, em última instância, definiriam o perfil dos novos paradigmas tecnológicos.

Hodgson vem se detendo, teoricamente, em estabelecer uma aproximação maior do conceito de instituição ao legado de Veblen, em que o mesmo deve necessariamente estar inserido em um ambiente analítico que contemple os indivíduos, seus hábitos, normas e padrões de conduta. Tal tarefa não é simples, pois exige a 
inclusão, na análise, de um ambiente de complexidade que contemple, de forma interativa, todos esses conceitos. Daí a proposição de que se avance no sentido da compreensão da noção de evolução, que tem em Veblen importante fonte teórica da aplicação dos princípios darwinianos às ciências sociais. Por essa razão, sugere-se que a relação entre o conceito de instituição e o processo de mudança (e, consequentemente, de crescimento) opere em um ambiente evolutivo. Mas, para isso, deve-se avançar na proposição de uma ontologia vebleniana, que contemple as relações de causalidade cumulativa que expliquem tais movimentos. E o preenchimento dessa lacuna só será possível mediante o avanço das novas linhas de pesquisa no campo de economia evolucionária e institucional centradas na mencionada ontologia.

\section{REFERÊNCIAS BIBLIOGRÁFICAS}

CONCEIÇÃO, Octavio A. C. (2008) “A dimensão institucional do processo de crescimento econômico: inovações e mudanças institucionais, rotinas e tecnologia social”. Economia e Sociedade, Campinas, v. 17, n. 1 (32), pp. 85-105.

GRANOVETTER, Mark. (1985) "Economic action and social structure: The problem of embeddedness”, American Journal of Sociology, v. 91, n. 3, pp. 481-510.

HODGSON, Geoffrey M. (1988) Economics and Institutions: A Manifesto for a Modern Institutional Economics, Polity Press and University of Pennsylvania Press, Cambridge and Philadelphia.

. (1993) Economics and Evolution: Bringing Life Back Into Economics, Polity Press and University of Michigan Press, Cambridge UK and Ann Arbor MI.

. (2000) "What Is the Essence of Institutional Economics?" Journal of Economic Issues 34.2: 317 329.

(2004) "Veblen and Darwinism," International Review of Sociology/Revue Internationale de Sociologie, Cambridge University, v. 14, n. 3.

. (2004a) "Darwinism, causality and the social sciences," Journal of Economic Methodology 11.2: $175-194$.

. (2004b) "Social Darwinism in Anglophone Academic Journals: A contribution to the history of the term," Journal of Historical Sociology, v. 17 n. 4, pp. 428-463.

. (2006) Economics in the Shadows of Darwin and Marx: Essays on Institutional and Evolutionary Themes, Edward Elgar, Cheltenham.

. (2006a) "What are institutions?" Journal of Economic Issues 40.1: 1-25.

. (2007) "The revival of Veblenian institutional economics," Journal of Economic Issues 41.2: 325 340.

LAWSON, T. (1997) Economics and Reality, Routledge, London and New York.

. (2005) “The nature of institutional economics," Evolutionary and Institutional Economics Review 2.1: 7-20.

. (2006) "The nature of heterodox economics," Cambridge Journal of Economics 30: 483-505.

NELSON, Richard R. e S. G. WINTER (1982) An Evolutionary Theory of Economic Change, Harvard University Press, Cambridge, MA.

. e WINTER, Sidney G. (2002) "Evolutionary theorizing in economics", Journal of Economic Perspectives. v. 16, n. 2, pp. 23-46.

NELSON, Richard R. (1995) "Recent evolutionary theorizing about economic change", Journal of Economic Literature 33.1: 48-90.

. (1998). "The agenda for growth theory: a different point of view", Cambridge Journal of Economics. v. 22, pp. 497-520. 
. e SAMPAT, Bhaven (2001) “Las instituciones como factor que regula el desempeño económico", Revista de Economia Institucional, n. 5, Segundo Semestre.

(2002) "Bringing institutions into evolutionary growth theory", Journal of Evolutionary Economics. Spring-Verlag. v. 12, pp. 17-28.

(2008) "What enables rapid economic progress: What are the needed institutions?" Research Policy, 37, pp. 1-11.

NORTH, Douglass C. (1990) Institutions, Institutional Change and Economic Performance. New York, Cambridge University Press.

. (1991) "Institutions," Journal of Economic Perspectives 5.1: 97-112.

. (1994) "Economic performance through time," American Economic Review 84.3: 359-367.

. (2005) Understanding the Process of Economic Change. Princeton and Oxford, Princeton University Press, 2005.

VEBLEN, Thorstein B. (1898) "Why is economics not an evolutionary science?" Quartely Journal of Economics 12.3: 373-397.

WILlIAMSON, Oliver E. (1985) Las Instituciones Económicas Del Capitalismo. México, Fondo de Cultura Económica.

. (1995) "Hierarquies, markets and power in the economy: An economic perspective", Industrial and Corporate Change. v. 4, n. 1, pp. 21-49. 